\title{
Game Bola Tangkis Berbasis Android Menggunakan App Inventor
}

\author{
Mhd Arief Hasan $^{1}$, Nurliana Nasution ${ }^{2}$, David Setiawan ${ }^{3}$ \\ 1,2 Program Studi Teknik Informatika Fakultas Ilmu Komputer Universitas Lancang Kuning \\ ${ }^{3}$ Program Studi Teknik Elektro Fakultas Teknik Universitas Lancang Kuning \\ Jln. Yos Sudarso Km 8 Pekanbaru, Telp. (+628117532015) \\ e-mail: ${ }^{1}$ m.arif@unilak.ac.id, ${ }^{2}$ nurliana@unilak.ac.id, ${ }^{3}$ dsetia@unilak.ac.id
}

\begin{abstract}
Abstrak
Berkembangnya teknologi yang berbasis mobile sekarang ini sudah sangat maju dan sering dipakai untuk dunia Information Technology (IT), bisnis, pendidikan dan media pembelajaran. Teknologi handphone yang saat ini berkembang pesat salah satunya adalah sistem operasi Android mobile (Android OS). Android adalah sistem operasi berbasis Linux yang dirancang untuk perangkat mobile layar sentuh yang memungkinkan perangkat lunak bebas dimodifikasi dan didistribusikan oleh pembuat perangkat, operator nirkabel dan pengembang aplikasi. Salah satu editor dalam pemrograman android adalah APP Inventor. App Inventor merupakan aplikasi web sumber terbuka yang awalnya dikembangkan oleh Google, dan saat ini dikelola oleh Massachusetts Institute of Technology (MIT). App Inventor memungkinkan pengguna baru untuk memprogram komputer untuk menciptakan aplikasi perangkat lunak bagi sistem operasi Android. Dengan adanya kemudahan dalam pembuatan program yang disediakan oleh App Inventor yang tidak diharuskan lagi untuk menuliskan koding. Sетиa fasilitas itu bisa digunakan dengan menggunakan klik drag menggunakan blog diagram. Maka peneliti mengambil kasus game bola tangkis dalam penelitian ini.
\end{abstract}

Kata kunci : Game Bola Tangkis, Android, App Inventor

\begin{abstract}
The development of mobile-based technology is now very advanced and often used for the world of Information Technology (IT), business, education and learning media. Mobile technology is currently growing rapidly one of them is the Android mobile operating system (Android OS). Android is a Linux-based operating system designed for touch-screen mobile devices that allows free software to be modified and distributed by device makers, wireless carriers and app developers. One of the editors in android programming is APP Inventor. Appper Inventor is an open source web application originally developed by Google, and is currently managed by the Massachusetts Institute of Technology (MIT). App Inventor allows new users to program computers to create software applications for the Android operating system. With the ease of making the program provided by App Inventor that no longer required to write coding. All facilities that can be used by using click drag using blog diagram. So researchers took the case of badminton games in this study.
\end{abstract}

Keywords : Badminton Games, Android, App Inventor.

\section{Pendahuluan}

Berkembangnya teknologi yang berbasis mobile sekarang ini sudah sangat maju dan sering dipakai untuk dunia Information Technology (IT), Bisnis, pendidikan dan media pembelajaran. Hal itu dibuktikan dengan gadget yang menggunakan android sebagai sistem operasiya. Fitur-fitur yang dimiliki juga sangat mudah dan nyaman untuk digunakan. Selain itu aplikasi dalam android 
sangatlah banyak, gratis dan mudah untuk di unduh. Maka banyak pihak yang tertarik untuk membuat aplikasi game, themes, kamus dan aplikasi lainnya.

Teknologi handphone yang saat ini berkembang pesat salah satunya adalah sistem operasi Android mobile (Android OS). Android adalah sistem operasi berbasis Linux yang dirancang untuk perangkat mobile layar sentuh yang memungkinkan perangkat lunak bebas dimodifikasi dan didistribusikan oleh pembuat perangkat, operator nirkabel dan pengembang aplikasi. Selain itu, Android memiliki sejumlah besar komunitas pengembang aplikasi (aplikasi) yang memperluas fungsionalitas perangkat. (Billy Hendrik, 2015). Diperkirakan ada 12 juta pengembang aplikasi seluler di seluruh dunia, untuk mewakili lebih dari setengah komunitas untuk global pengembangan dan hampir setengahnya memusatkan perhatian mereka pada Google Android. Jumlah pengembangan diperkirakan akan mencapai 14 juta pada 2020 (Boxall, 2016).

App Inventor merupakan aplikasi web sumber terbuka yang awalnya dikembangkan oleh Google, dan saat ini dikelola oleh Massachusetts Institute of Technology (MIT). App Inventor memungkinkan pengguna baru untuk memprogram komputer untuk menciptakan aplikasi perangkat lunak bagi sistem operasi Android. App Inventor menggunakan antarmuka grafis, serupa dengan antarmuka pengguna pada Scratch dan Star Logo TNG, yang memungkinkan pengguna untuk men-drag-and-drop objek visual untuk menciptakan aplikasi yang bisa dijalankan pada perangkat Android. Dalam menciptakan App Inventor, Google telah melakukan riset yang berhubungan dengan komputasi edukasional dan menyelesaikan lingkungan pengembangan online Google. Pada App Inventor ini terdapat beberapa komponen yang terdiri dari: (1) Komponen desainer yang berjalan pada browser digunakan untuk memilih komponen yang diperlukan untuk mengatur propertynya. Pada komponen desainer sendiri terdapat 5 bagian, yaitu : palette, viewer, component, media dan properties; (2) Block Editor berjalan di luar browser dan digunakan untuk membuat serta mengatur behaviour dari komponenkomponen yang akan kita pilih dari komponen desainer; (3) Emulator yang digunakan untuk menjalankan dan menguji project yang telah dibuat (Wolber, 2011).

Hal ini kemudahan dalam pembuatan program dan tidak diharuskan lagi untuk menuliskan koding. Semua fasilitas itu bisa digunakan dengan menggunakan klik drag menggunakan blog diagram. Dengan alasan diatas, maka peneliti mengambil kasus game bola tangkis dalam penelitian ini.

Pada penelitian ini akan dibuat sebuah game yang bergenre ketangkasan sebagai sarana hiburan user. Game ini berupa bola yang dihadapkan terhadap rintangan yang ada dalam game. Beberapa objek ditambahkan sebagai media rintangan kesulitan yang terdapat dalam game. Keberhasilan dari game ini adalah user bisa mendapatkan point tertinggi dalam permainan game.

\section{Tinjauan Pustaka}

Game serta manfaatnya game merupakan aktifitas terstruktur atau semiterstruktur yang mengandung unsur menarik dan menyenangkan. Umumnya untuk tujuan hiburan. Berdasarkan tipenya terdiri dari tiga jenis yakni Role Play Game (RPG), Real Time Strategy (RTS) dan FPS atau First Person Shooter (Martono, 2015). Game bisa terdiri dari beberapa genre game yang masingmasing memiliki karakteristik tersendiri yakni : Adventure, Action Racing, Arcade, Logic, Board Games (Permainan Papan), Simulation, dan Education.

Menurut Sugeng (2009), kriteria media berbasis komputer yang baik haruslah memenuhi persyaratan sebagai berikut :

1. Kesesuaian dengan tujuan meliputi : sesuai dengan kompetensi dasar dan indikator yang telah ditetapkan.

2. Kesesuaian dengan tujuan meliputi : sesuai dengan materi, tidak ada kesalahan konsep dan mendukung pemahaman materi.

3. Efisiensi waktu meliputi : pembuatan dan penggunaan media pembelajaran harus sesuai dengan waktu yang telah disediakan.

Jenis-jenis game tersebut dapat mudah dikenali sifatnya dan mudah ditemukan di google playstore. Beberapa genregame bukan hanya mampu berdiri sendiri, namun juga dapat 
digabungkan (mixed atau hybrid) sehingga unsur permainan lebih bervariasi, menantang dan yang paling penting adalah mengandung unsur edukasi. Kehadiran game dapat membantu untuk menumbuhkan kembali motivasi belajar anak yang mengalami penurunan semangat belajar karena didalamnya terdapat threatment tertentu untuk memancing minat belajar anak terhadap materi pelajaran.

Android adalah sistem operasi untuk telepon seluler yang berbasis Linux (Nasrudin Safaat H., 2011, h.1). Android menyediakan platform terbuka bagi para pengembang untuk menciptakan aplikasi mereka sendiri yang digunakan oleh bermacam peranti bergerak. Awalnya, Google Inc. membeli Android Inc., pendatang baru yang membuat peranti lunak untuk ponsel. Kemudian untuk mengembangkan Android, dibentuklah Open Handset Alliance, konsorsium dari 34 perusahaan peranti keras, peranti lunak, dan telekomunikasi, termasuk Google, HTC, Intel, Motorola, Qualcomm, T-Mobile, dan Nvidia.

App Inventor adalah Perangkat mobile sangat populer karena tersedianya berbagai aplikasi mobile yang mudah digunakan. Aplikasi mobile telah meningkatkan minat pendidik karena mereka dapat memfasilitasi pengajaran dan pembelajaran (L. Johnson, 2012). Untuk membuat aplikasi mobile merupakan tantangan bagi siapa saja tanpa pengalaman pemrograman sebelumnya. Beberapa bahasa pemrograman visual telah dikembangkan untuk mengatasi tantangan ini.

MIT App Inventor adalah bahasa pemrograman berbasis blok visual. Ini awalnya produk Google, namun kemudian dirilis sebagai perangkat lunak sumber terbuka yang dikelola oleh Massachusetts Institute of Technology. MIT App Inventor memungkinkan nonprogrammers untuk membuat aplikasi mobile untuk perangkat yang menjalankan sistem operasi Android dan mampu mengembangkan semua jenis aplikasi, tidak hanya animasi.

MIT App Inventor memiliki dua jendela utama: Designer Komponen (Gambar 1) untuk membangun antar muka pengguna dan Editor Blok (Gambar 2) untuk menentukan perilaku aplikasi. Perancang Komponen memungkinkan pemilihan "komponen" (objek dari kelas tertentu) yang akan ditambahkan, dengan menyeretnya ke tata letak layar, sebagai bagian dari aplikasi. Setelah bagian ditambahkan ke aplikasi, propertinya dapat ditetapkan. Editor Blok menggunakan teka-teki "kerangka" gambar (metode kelas terkait) yang digabungkan untuk menentukan perilaku aplikasi sebagai respons terhadap berbagai peristiwa. Pengguna dapat menguji aplikasi mereka secara langsung di ponsel Android atau emulator dari ponsel yang berjalan di komputer. MIT App Inventor memungkinkan siswa untuk dapat fokus pada aspek-aspek yang menarik dari pemecahan masalah desain pemrograman dan dapat membangun aplikasi mobile yang kreatif. MIT App Inventor server juga dapat menyimpan semua proyek serta memungkinkan pengguna bisa masuk ke akun mereka untuk melanjutkan pekerjaan kapan dan dimana saja.

MIT App Inventor dapat memungkinkan siswa non Ilmu komputer (CS) untuk bida mengakses semua fitur perangkat mobile dan memberikan cara mudah dalam membangun aplikasi yang berguna. MIT App Inventor sangat kaya fitur, memiliki komponen untuk menerima teks SMS, mengirim pesan, membaca sensor GPS, dan berkomunikasi dengan sumber web eksternal. Dengan menggunakan sensor GPS, siswa dapat mengembangkan aplikasi untuk membantu orang menemukan dirinya dan potensi bahaya. Siswa juga dapat mengembangkan aplikasi untuk mengirimkan peringatan jika terjadi keadaan darurat. MIT App Inventor adalah Java-ased dan memberikan pengenalan yang baik tentang paradigma berorientasi objek. Hal ini juga dapat memberikan dasar yang baik untuk memperoleh keterampilan komputasi yang lebih maju.

Sekarang, Editor Blok hanyalah mode yang berbeda dalam proyek dan dapat dilihat dari browser web. Satu-satunya download yang dibutuhkan untuk App Inventor 2 adalah emulator. Namun jika pengguna memiliki perangkat Android, emulator tidak diperlukan dan tidak perlu dipasang. 


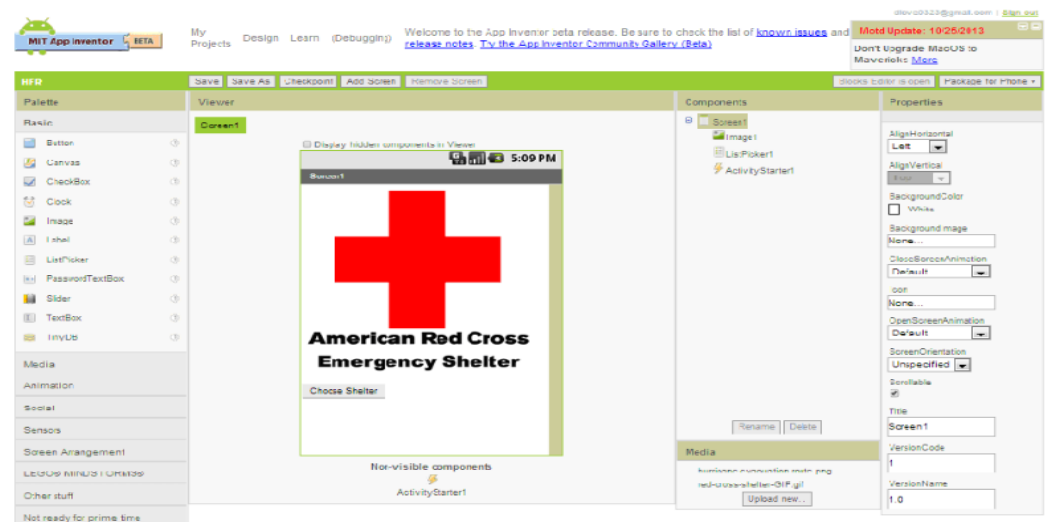

Gambar 1. Perancang Komponen

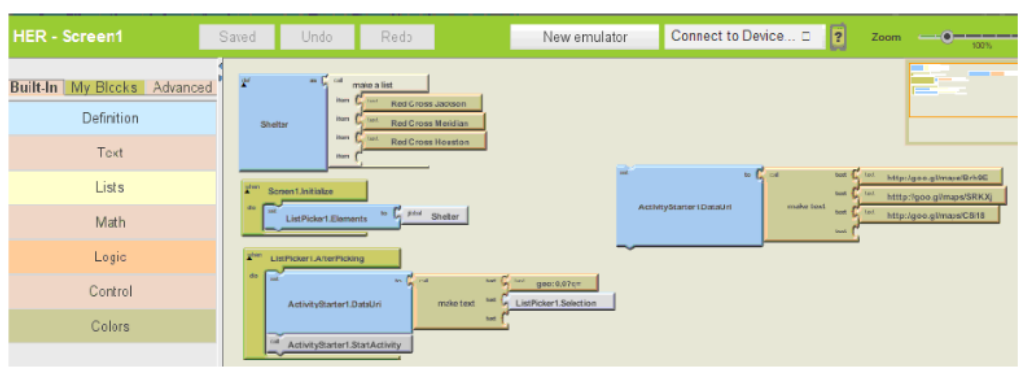

Gambar 2. Blok Editor

\section{Penelitian Yang Relevan}

Penelitian yang dilakukan oleh Hsu Y, et al (2012) tentang pemberdayaan pendidik menggunakan App Inventor pada Android, yang memungkinkan untuk melakukan perancangan workshop secara online. Aplikasi perancangan workshop ini ditawarkan melalui Boise State University Professional Development (PD) Portal, host pada sistem manajemen pembelajaran Moodle (disediakan oleh Moodlerooms, Inc yang berbasis di Baltimore, MD, USA). Tujuan dari workshop ini adalah untuk membantu peserta memanfaatkan potensi teknologi komputasi mobile untuk membantu para pendidik dalam mengajar, belajar dan bekerja. Dalam workshop ini, peserta membahas tentang mobile learning dan aplikasi favorit melalui Twitter dengan memasukkan hashtag.

Penelitian yang dilakukan oleh Feeney, K. K. (2013) tentang mendorong kolaborasi melalui App Inventor. Pada saat rilis open source, App Inventor tidak memiliki sumber daya yang penting untuk mendukung kolaborasi : dokumentasi untuk kode sumber kontributor dan dukungan teknologi bagi pengguna untuk mengembangkan aplikasi dalam kelompok lingkungan hidup. Untuk mengatasi masalah ini, peneliti menambahkan properti ke dalam komponen yang ada kemudian menciptakan dokumentasi terperinci tentang proses untuk pengembangan ke depan. Peneliti juga menciptakan alat untuk penggabungan beberapa proyek, yang akan mendorong kerja tim yang memungkinkan beberapa pengguna untuk membuat kode program secara terpisah kemudian menggabungkan kembali kode program tersebut. Kontribusi pada penelitian ini akan meningkatkan kolaborasi antar pengguna serta pengembang App Inventor.

Penelitian yang dilakukan oleh Kang, H., et al (2015) tentang penerapan aplikasi App Inventor dalam pembuatan purwarupa pembelajaran berbasis Android. Pemrograman pada App Inventor memungkinkan pengembang aplikasi mobile untuk fokus pada desain dan pemrograman logika bukan sintaks bahasa. Proses pengembangan aplikasi terdiri dari lima tahap, yaitu 
perencanaan, pemodelan, pembuatan purwarupa, implementasi dan pendistribusian. Dalam proses desain perangkat lunak, umumnya arsitektur perangkat lunak dibagi menjadi komponen yang disebut modul. Peneliti menganalisis bahwa modul terdiri dari blok yang terkait dengan App Inventor. Melalui penerapan App Inventor sebagai metode pembuatan purwarupa berbasis Android, memungkinkan aplikasi mobile android untuk digunakan lebih cepat. Pada penelitian ini, menunjukkan bahwa proses pembangunan menggunakan App Inventor sebagai metode pembuatan purwarupa lebih efisien dibandingkan dengan menggunakan SDK Android saja.

\section{Metode Penelitian}

Untuk menghasilkan game yang sesuai dengan tujuan pendidikan serta dapat memenuhi aspek-aspek yang diinginkan, maka harus dilakukan dengan suatucara atau pendekatan, yakni melalui model R\&D yang sudah terstandardisasi. Penulis menggunakan pengembangan multimedia menurut Ariesto Hadi Sutopo tahun 2003 yang terdiri dari 6 tahapan, yaitu concept, design, material collecting, assembly, testing dan distribution seperti yang ditunjukkan pada Gambar 3.

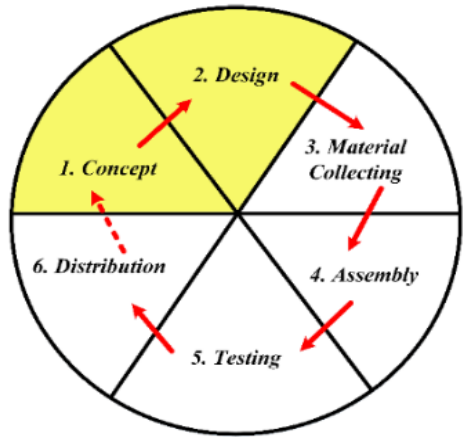

\section{Gambar 3. Model Pengembangan Game (Hadi, 2003)}

Pemilihan ini berdasarkan pertimbangan, yakni sifatnya sederhana dan terstruktur secara sistematis, mudah untuk dipelajari dan diaplikasikan. Penelitian ini dalam tahap concept dan design sebagaimana yang di blok warna kuning pada Gambar 3. diatas untuk Concept merupakan tahap awal yang digunakan oleh penulis yang berisimengenai deskripsi, tujuan, manfaat dan target audiens. Design bersisi spesifikasi perangkat keras, story board, kebutuhan audio, karakter dan property yang diguanakan, rintangan dan award, use case diagram. Story board merupakan gambaran scenario yang dibuat secara bertahap yakni setiap scene dalam game.

\section{Hasil dan Pembahasan}

\subsection{Concept}

Game singkat ini bertujuan untuk permainan mengasah ketangkasan dalam mengarahkan bola agar tidak jatuh kedalam jurang. Halangan dan rintangan dibuat dalam game ini ditujukan untuk kesulitan yang dihadapi dalam permainan game ini. Permainan ini bersifat single player dimana prestasi user disini ditinjau dari total skor yang didapatkan selama permainan game ini.

\subsection{Design}

Sebelum menentukan kebutuhan perangkat keras, tentunya harus diperhatikan aplikasi yang akan digunakan dalam proses pengembangan. Berikut ini spesifikasi kebutuhan perangkat lunak yang digunakan selama proses pengembangan pada penelitian ini. Sistem Operasi Windows 8, , browser untuk mengakses MIT APP inventor, CorelDraw Xsuite \& Photoshop CS6 dan Editor 
Suara menggunakan sound maker. Sedangkan perangkat keras adalah processor minimum Pentium Core i3, Memory4 GB DDR2, VGA Onboard (minimal 1 GB) dan sound card stereo multimedia.

Penggunaan audio dalam game ini adalah : intro, jalan, bola berjalan dan mengenai rintangan, meloncat, jatuh, gagal, berhasil, ucapan terimakasih dan, "Mission Complete".

Ada beberapa item image utama yang selalu ada dalam setiap level permainan

Tabel 1 : Tabel Objek dalam Game

\begin{tabular}{|c|c|}
\hline ITEM & FUNGSI \\
\hline Bola & $\begin{array}{l}\text { - Objek utama dalam game yang diarahkan } \\
\text { user menuju sasaran }\end{array}$ \\
\hline Api & $\begin{array}{l}\text { - Api merupakan objek perintang dalam } \\
\text { game ini }\end{array}$ \\
\hline $\begin{array}{r}\text { Garis Tebal } \\
\text { Garis Tipis } \\
\text { Garis Tipis Sekali }\end{array}$ & $\begin{array}{l}\text { - Garis tebal, tipis, dan tipis sekali } \\
\text { merupakan objek penghalang dalam } \\
\text { rintangan bola }\end{array}$ \\
\hline Pemukul & $\begin{array}{lll}\text { - } & \text { Pemukul merupakan objek yang } \\
\text { digunakan untuk mengarahkan bola }\end{array}$ \\
\hline Pusaran & $\begin{array}{l}\text { - Pusaran merupakan tujuan akhir bola } \\
\text { diarahkan setelah melewati rintangan dan } \\
\text { setelah bola masuk ke pusaran maka user } \\
\text { boleh lanjut ke level berikutnya }\end{array}$ \\
\hline Win dan & $\begin{array}{l}\text { - Objek win dan lose ini digunakan untuk } \\
\text { mengakhiri atau meneruskan permainan }\end{array}$ \\
\hline
\end{tabular}

Fungsi-fungsi yang dilakukan pada aplikasi game bola tangkis ini dapat dijelaskan melalui use case, activity, class diagram dan sequence diagram berikut ini.

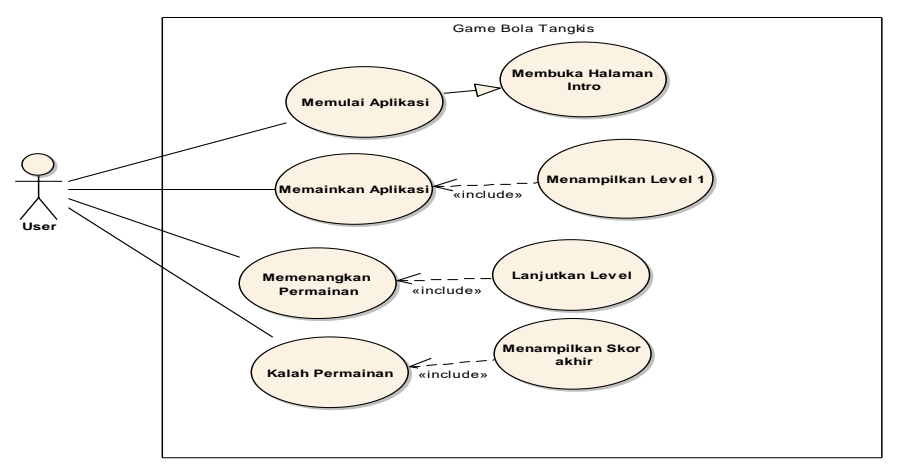

Gambar 4. Use Case Diagram Game Bola Tangkis 


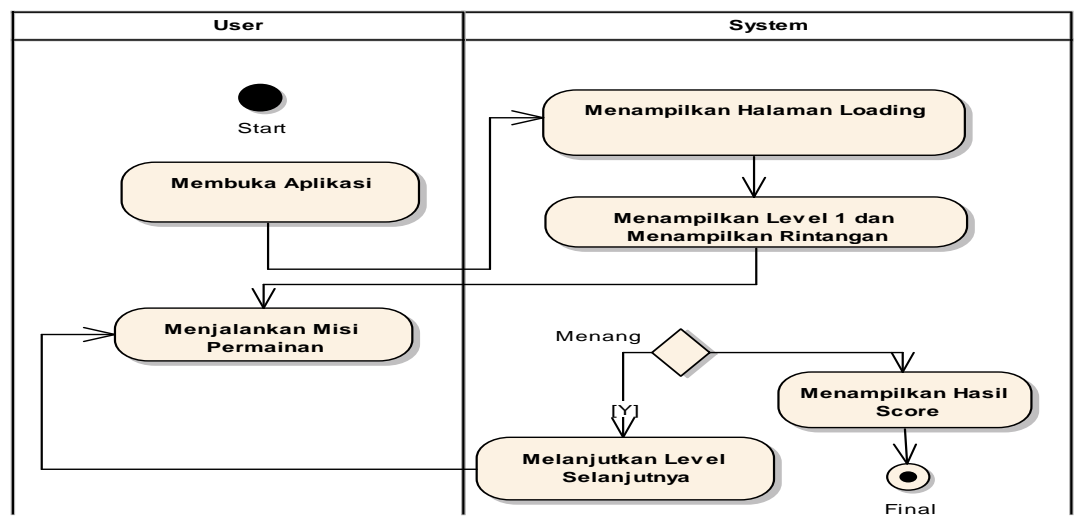

Gambar 5. Activity Diagram Game Bola Tangkis

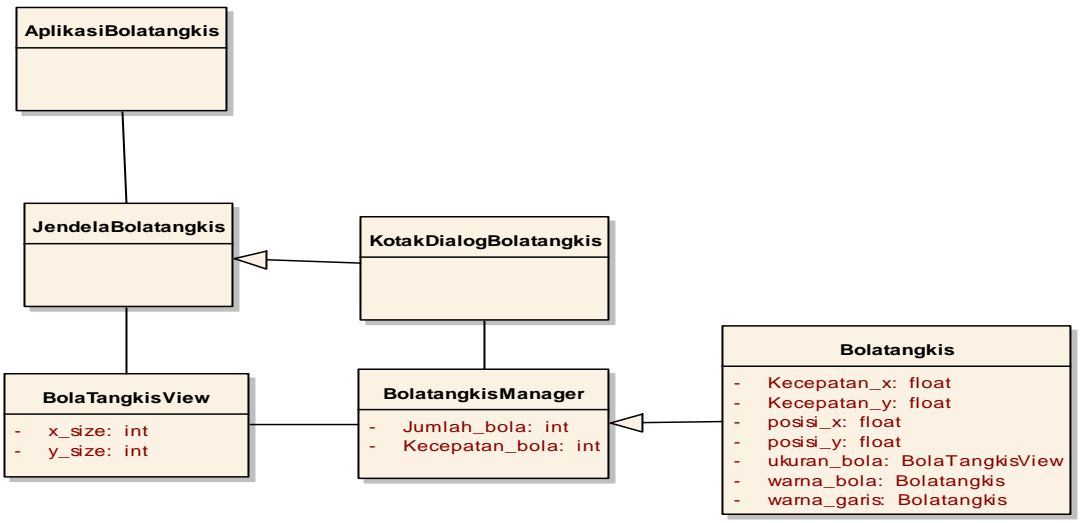

Gambar 6. Class Diagram Game Bola Tangkis

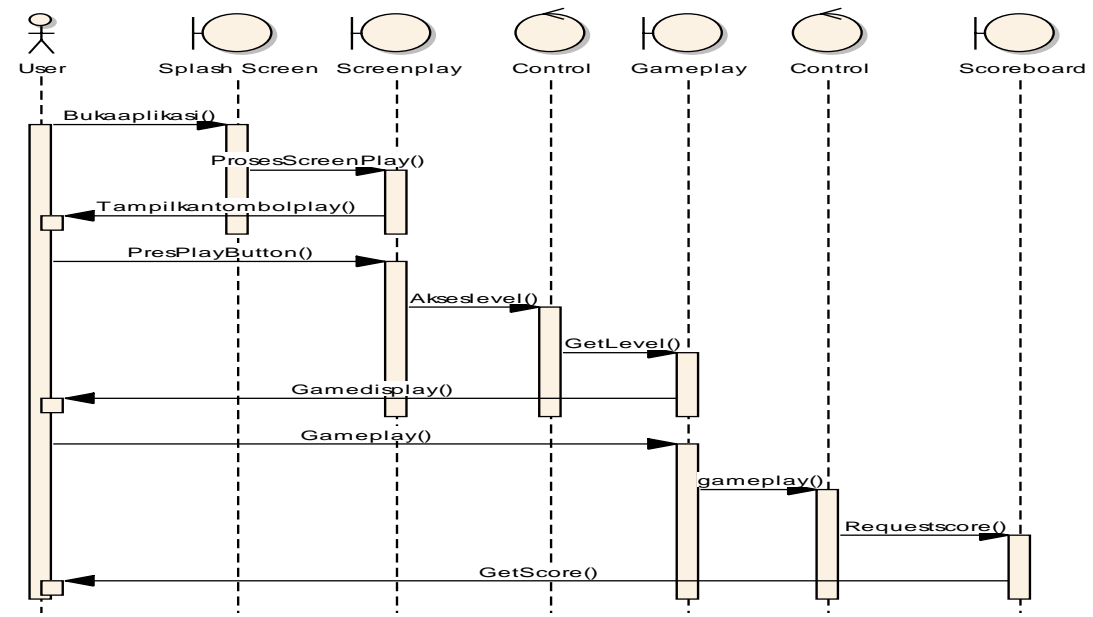

Gambar 7. Sequence Diagram Game Bola Tangkis 
Desain antarmuka yang pertama yaitu halaman utama. Tampilan ini akan muncul pada awal user membuka aplikasi. Halaman pertama ini menyajikan mengenai aturan permainan. Ada tombol menekan untuk memulai aplikasi. Sehingga user langsung dihadapkan terhadap level utama dari aplikasi ini. User bisa menggunakan touchscreen dengan menyentuh tongkat (warna biru) untuk mengarahkan bola ke dalam pusaran. Berikut layout tampilan game yang terbentuk.

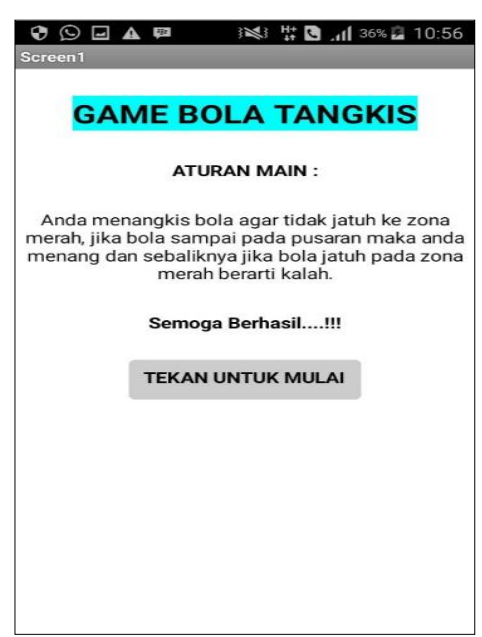

Gambar 8. Halaman Menu Utama

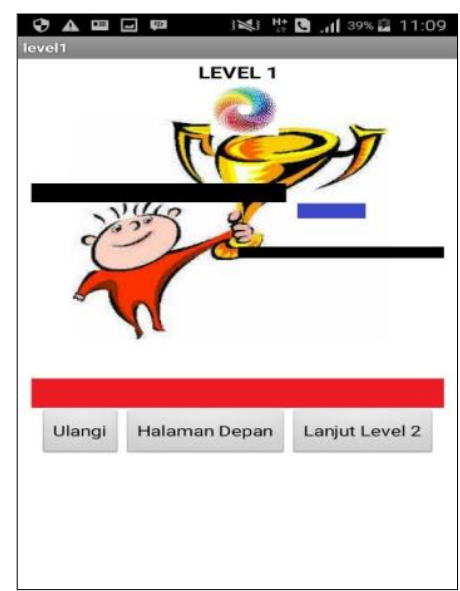

Gambar 10. Halaman Ketika Menang

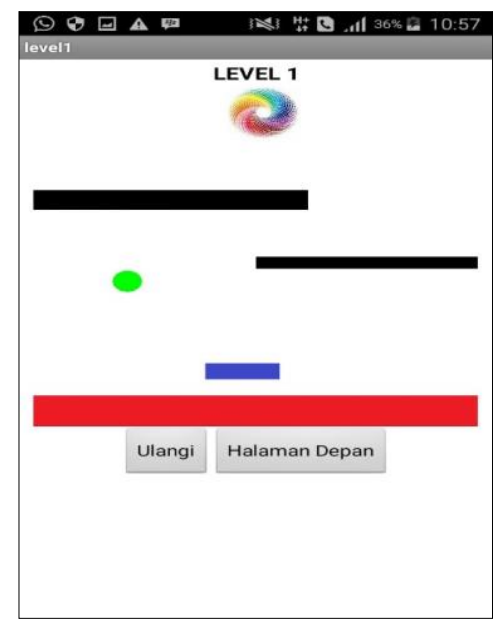

Gambar 9. Halaman Level 1

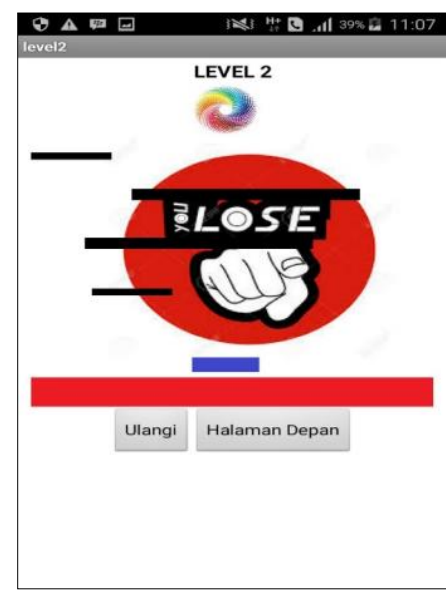

Dari implementasi program di atas, merupakan suatu kesatuan utuh yang tak terpisahkan dari blok diagram yang terbentuk menggunakan App Inventor. Blok diagram ditujukan untuk mengatur layanan perintah yang diberikan kepada masing-masing objek agar bisa berjalan sesuai dengan desain perspektif yang dibentuk. Berikut ini adalah beberapa blok diagram yang terjadi dari pembuatan aplikasi bola tangkis. 

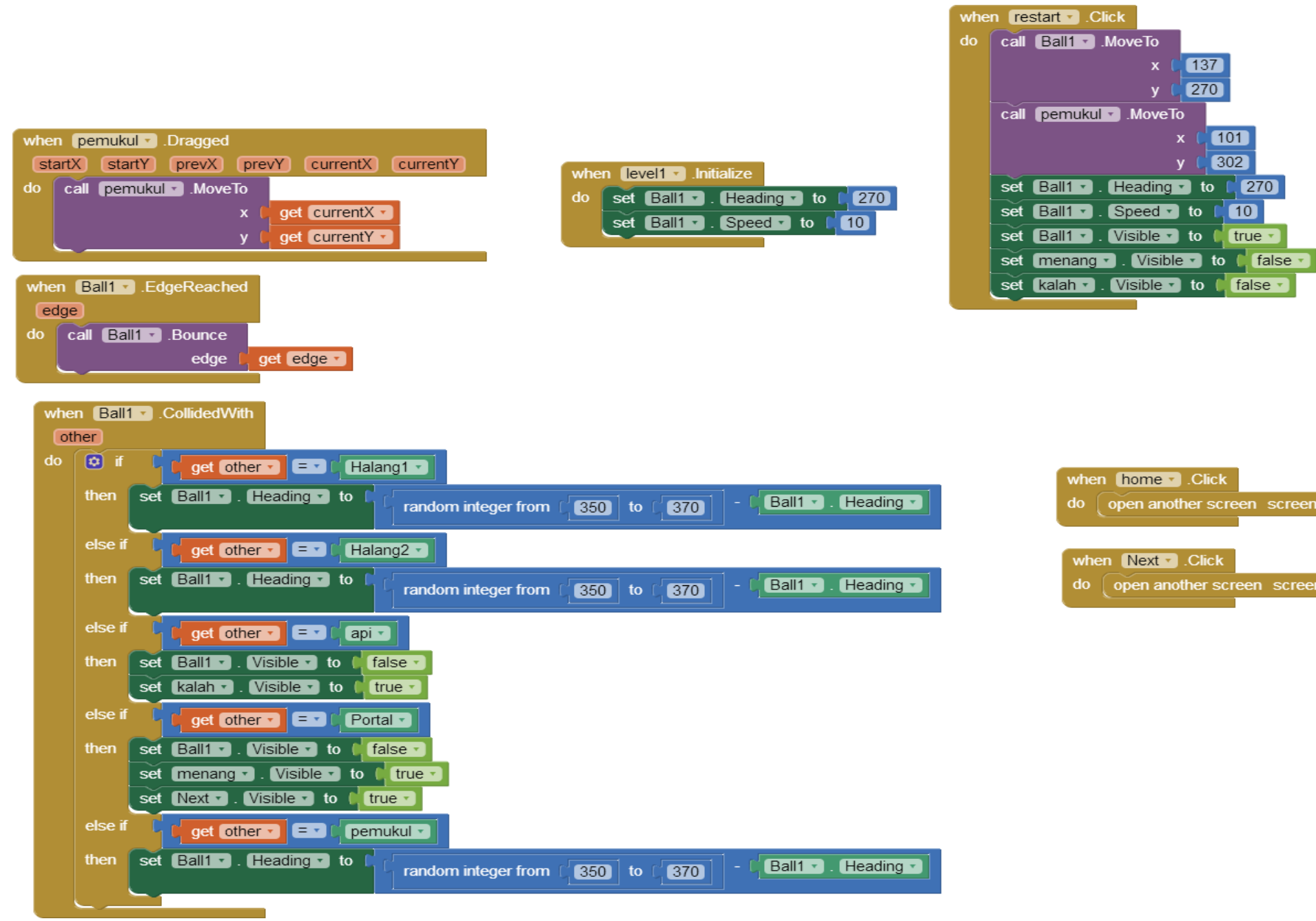

when home - Click

do open another screen screenName " "Screen1"

when Next - Click

do Open another screen screenName " level2 "

Gambar 12 Blok Diagram Bola Tangkis 


\section{Kesimpulan}

Penelitian ini menggunakan model pengembangan dengan tahapan penelitian terbatas pada siklus pertama dan kedua yakni : concept dan design. Pada tahap Concept penulis mendeskripsikan game, merumuskan tujuan pembuatan game, manfaat apa yang didapatkan. Pada tahap Design penulis telah menentukan spesifikasi perangkat keras dan perangkat lunak, menyusun story board, audio, karakter dan property yang diguanakan dalam game, mendeskripsikan rintangan dan award dalam beberapa scene, dan membuat use cese diagram.

Permainanan bola tangkis ini adalah game sederhana yang bisa dikembangkan lebih lanjut untuk kebutuhan lainnya. Efek-efek lain bisa diberikan untuk memberikan game ini lebih variatif. Pada penelitian ini hanya bersifat permainan dasar dan bisa dikembangkan terus oleh para pembaca agar bisa betul-betul mengarah kepada target konsumen yang diinginkan.

\section{Daftar Pustaka}

[1] A. Suhendar, S. H. (2002). Visual Modeling Menggunakan UML dan Rational . Bandung: Informatika.

[2] Billy Hendrik, M. M. (2015). Pemanfaatan MIT APP INVENTOR 2 Dalam Membangun Aplikasi Pengontrolan Kecepatan Putaran Motor Listrik. Jurnal Teknologi Informasi dan Pendidikan ISSN 2086-4981, Volume 8 Tahun 2015.

[3] Boxall, A. (2016, October Jumat). There are 12 million mobile developers worldwide, and nearly half develop for Android first. Retrieved from businessofapps: http://www.businessofapps.com/12-million-mobile-developers-worldwide-nearly-halfdevelop-android-first/

[4] Fuada, S. (2015). Perancangan Game Petualangan Pramuka Berbasis Android. JUPITER-Jurnal Penerapan Ilmu-Ilmu Komputer .

[5] Hadi, S. (2003). Multimedia interaktif dan flash. Yogyakarta: Graha Ilmu.

[6] Hsu, Y. e. (2012). Empowering educators with Google's Android App Inventor: An online orkshop in mobile app design. British journal of educational technology ISSN: 0007 1013 Date: 01/01/2012, Volume: 43 Issue: 1 Page: E1-E5 DOI: 10.1111/j.14678535.2011.01241.x.

[7] Kang, H. e. (2015). Application Study on Android Application Prototyping Method using App Inventor. Indian Journal of Science and Technology, Volume 8, Issue 18.

[8] L. Johnson, S. A. (2012). Mobile apps. The NMC horizon report: 2012 higher education edition. Austin, Texas: The New Media Consortium.

[9] Martono, K. (2015). Pengembangan Game dengan Menggunakan Game Engine Game Maker. Jurnal Sistem Komputer, 23-30 .

[10] Wolber, D. e. (2011). App Inventor, Create Your Own Android Apps. Gravenstein Highway North: O’Reilly Media, Inc. 